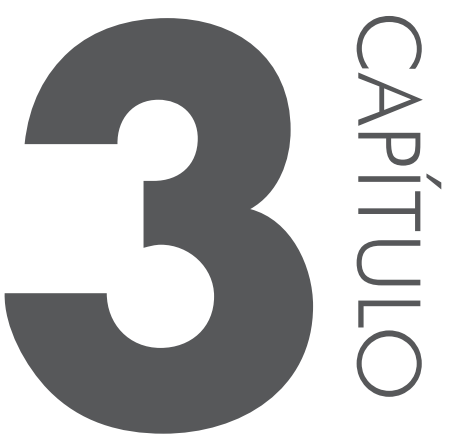

\title{
ENTRE A HISTÓRIA E A CIÊNCIA: A CONSTITUIC̣ÃO DA HISTORIOGRAFIA DA LINGUÍSTICA COMO ÁREA DE PESQUISA E ENSINO NOS ESTUDOS SOBRE A LINGUAGEM
}

Neusa Barbosa Bastos

Universidade Presbiteriana Mackenzie Pontifícia Universidade Católica de São Paulo

Ronaldo de Oliveira Batista Universidade Presbiteriana Mackenzie 


\subsection{INTRODUC̣ÃO}

Apresentar a um público mais amplo a área que, desde o final da década de 1970, se identifica como Historiografia da Linguística (HL) é nosso mister neste capítulo que tem como objetivo principal delinear um campo que coloca como tarefa analisar períodos da história dos estudos sobre a linguagem em diferentes recortes temporais ${ }^{1}$. Ao apontar características e direcionamentos da perspectiva historiográfica sobre a ciência da linguagem, o texto coloca em discussão proposições de procedimentos metodológicos para o campo, além de mapear especificidades de uma historiografia da linguística brasileira, seus projetos e grupos de especialidade e também sua inserção na formação de docentes e pesquisadores na área de Letras.

Para direcionar a perspectiva adotada neste texto, lembramos as reflexões de Marc Bloch sobre o ofício do historiador (BLOCH, 2001), pois elas encontram paralelo na busca do historiógrafo da linguística Pierre Swiggers (1991) por definições e horizontes para a prática de historiografar os estudos sobre a linguagem. Se Bloch insistia na não transparência dos textos e dos documentos históricos, sendo necessário ultrapassar sua superfície para atingir a compreensão do que eles nos podem transmitir, Swiggers propõe uma arqueologia do saber linguístico a partir da imagem de um pesquisador que deve escavar nas camadas mais superficiais para atingir o que os documentos nos dizem além das aparências dos estados das coisas. O movimento é semelhante ao do arqueólogo, já que, como este, o historiógrafo não retira a "terra" em busca somente de vestígios por eles mesmos, mas afasta a poeira dos saberes solidificados em posicionamentos canonizados para compreender estágios de formação e desenvolvimento do conhecimento sobre a linguagem, tendo em mente interpretações que possam ampliar nossa percepção dos alcances do passado em relação com preocupações do presente, em um movimento contínuo de retroalimentação, e não de imediata causalidade ou

1 A discussão a respeito da nomeação da área como Historiografia da Linguística ou Historiografia Linguística não é colocada aqui neste texto. Para uma introdução a esse debate, consultar Batista (2013) e observar a citação que segue: "Pode-se chamar de 'historiografia' a produção dos historiadores, para diferenciá-la da 'história' - entendida como um conjunto de situações e acontecimentos pertencentes a uma época e a uma região -, que é o objeto de estudo dos historiadores. Temos, assim, dois níveis distintos. Pode-se considerar que a história existe independentemente da existência dos historiadores (a menos que se adote uma postura filosófica idealista). Ela é constituída por um encadeamento de atividades humanas ocorridas ao longo do tempo. A historiografia, por outro lado, é o produto primário da atividade dos historiadores. Ela é composta essencialmente por textos escritos e reflete sobre os acontecimentos históricos agregando-lhes um caráter discursivo novo. Procura desvendar aspectos da história, mas não é uma mera descrição da realidade histórica.” (MARTINS, 2005, p. 115-116). 
implicação ${ }^{2}$, caracterizando, assim, a atividade histórica como uma busca direcionada por interrogações e problematizações.

Um campo que se propõe analisar o desenvolvimento do conhecimento sobre a linguagem possui um caráter genético, por assim dizer, pois busca compreender a formação, a elaboração e o desenvolvimento de conceitos e técnicas de análise, inseridos, inevitavelmente, em contextos sociais constituídos por comunidades intelectuais. Historiografar a linguística é, portanto, tarefa que não pode deixar de lado a observação de caráter social que coloca o saber inserido em uma complexa rede discursiva, com as projeções de imagens e lugares de dizer que, em sua essência, são parte da própria constituição do conhecimento intelectual (cf. BATISTA, 2013).

Nesse sentido é que a concepção murrayniana (MURRAY, 1994) vigente nos seus estudos acerca da teoria de grupos nos leva à discussão do ethos do cientista, ponto que nos parece fundamental para colocar em perspectiva os espaços de atuação da HL. Referindo-nos ao conceito de ethos, retornamos ao século I a.C, com Aristóteles, que nos apresenta três espécies de provas empregadas pelo orador com o intuito de persuadir seu auditório. Primeiro: a questão do caráter do orador (o ethos); segundo: as paixões despertadas nos ouvintes (o pathos); terceiro: o próprio discurso (o logos). Para que se possa persuadir o público, é necessário impressionar, seduzir e fundamentar ${ }^{3}$. $\mathrm{O}$ ethos está relacionado às propriedades que os oradores se conferem implicitamente, pela sua maneira de dizer: não o que dizem a propósito deles mesmos, mas o que mostram pelo próprio modo de se expressar, revelando três qualidades importantes do orador para dar uma imagem positiva de si mesmo: a prudência (phronesis), que consiste em ponderar sobre o discurso; a benevolência (eunóia), que remete à transmissão de uma imagem agradável de si próprio e a virtude (aretè), que implica transmitir uma ideia de simplicidade e sinceridade.

Dessa forma, construído no próprio ato de enunciação, também o cientista expõe uma postura que governa o seu comportamento. Feita a escolha teórica pelos enunciadores do modelo a ser divulgado, persuadem-se os enunciatários a aderir a grupo de especialidade que triunfará assim que se apresentem novas contribuições ao avanço dos estudos de determinada área de conhecimento e suas subáreas.

2 "Prudente, isto é, que não transporte ingenuamente o presente para o passado e que não procure por outras vias um trajeto linear que seria tão ilusório quanto o sentido contrário.” (LE GOFF, 1984, p. 162).

3 Já no século XXI, auxiliando-nos de textos de Maingueneau (2010, p. 79), podemos citar: "O ethos discursivo é coextensivo a toda enunciação: o destinatário é necessariamente levado a construir uma representação do locutor que este último tenta controlar mais ou menos conscientemente e de maneira bastante variável, segundo os gêneros do discurso". 
Desse modo, para que a HL possa fazer suas análises, levando em consideração a complexidade de seu objeto de estudo (teorias e procedimentos de observação sobre as línguas, constituição de grupos de especialidade/pesquisa, continuidade e rupturas na história intelectual, entre outros), como vimos envolto em uma rede discursiva e social, estabelece-se, de acordo com Koerner (2007, p. 61), uma lista de princípios práticos e teóricos que devem ser amplos o suficiente para encontrar aceitação entre historiógrafos da linguística, que os adaptam a períodos diferentes da história das ciências da linguagem e a aspectos particulares sob investigação, o que parametriza as linhas guias que poderão fazer nossa interpretação do passado mais acessível para leitores que não necessariamente compartilhem da mesma formação e interesse e que poderão a partir disso compreender diferentes caminhos que levam um grupo a se constituir e se institucionalizar, oferecendo maior probabilidade de consolidação, elaboração e difusão de um conjunto de ideias.

Imerso nessa proposta de análise de eventos e aspectos da história dos estudos sobre a linguagem (inclusive aqueles que pertencem a recortes temporais distantes do momento de constituição da linguística como ciência), em 1996 (aqui considerado como marco temporal relevante para a constituição da área no contexto brasileiro), iniciou-se o Grupo de Trabalho em Historiografia da Linguística Brasileira (GTHLB), ligado à Associação Nacional de Pós-Graduação em Letras e Linguística (ANPOLL), por intermédio, com apoio de outros pesquisadores da área, de Cristina Altman (USP), que foi uma das fundadoras do Grupo e mantinha, na época, contato com linguistas europeus voltados para as questões da HL.

Nas próximas seções, este texto pretende apresentar a HL e suas especificidades e também delinear elementos que contribuíram para a formação do campo no cenário acadêmico brasileiro, em meio a influências e embates por sua institucionalização.

\subsection{A HISTORIOGRAFIA DA LINGUÍSTICA: DEFINIC̣ÕES, PROCEDIMENTOS, FRONTEIRAS E DIÁLOGOS}

A Historiografia da Linguística (HL), pela própria definição de seu objeto de estudo e articulação de alguns de seus procedimentos metodológicos, situa-se em uma zona de fronteira entre a Linguística e a História. Assim, a natureza epistemológica do campo coloca em situação de diálogos e intermediações fundamentos da ciência da linguagem e fundamentos teóricos da pesquisa histórica. Será nessa dimensão que o estatuto da disciplina e da área de pesquisa e ensino vai se constituir, traçando, inevitavelmente, o aspecto interdisciplinar de seus elementos teóricos e diretrizes metodológicas.

Observar eventos e episódios históricos nos permite entender a sucessão temporal como parte de um processo que coloca em diálogo os tempos do passado, 
do presente e também do futuro, em uma construção de memórias, projeções e identidades. Dessa forma, uma interpretação do decurso histórico, suas causas e consequências, não funciona apenas para retardar o esquecimento, como era no nascimento da narrativa histórica com o grego Heródoto. Trata-se, sim, da presença de outra necessidade: a da compreensão, pois a historiografia coloca-se como um discurso de observação sobre o conjunto de eventos que caracterizam a corrente histórica.

Seguindo Swiggers (1983), é possível delinear uma observação epistemológica da HL analisando sua constituição a partir de um componente metatórico, ou seja, seu estatuto científico, seu objeto e os limites dos alcances analíticos, sua caracterização formal, seu espaço em meio a outras disciplinas e as formas de comunicação entre os historiógrafos. A partir dessa perspectiva, a HL se caracteriza como uma disciplina científica que tem por objetivo estruturar seu objeto de estudo numa série de relações sistemáticas, levando também em conta observações derivadas das abordagens da metodologia da linguística e da história das ideias (SWIGGERS, 1983, p. 61).

Conforme a essa definição do estatuto e de seu objeto, há a caracterização da HL como metaciência, já que se analisam práticas de uma ciência ou área de saber. A historiografia a respeito dos estudos da linguagem não toma como objeto as línguas e seus fenômenos, mas o que foi dito e se diz a respeito dessas línguas e suas propriedades, nos diversos ramos da linguística, da filologia e da gramática (entre outras áreas), como a morfologia, a sintaxe, a semântica, a pragmática, os estudos do discurso, entre outros - os trabalhos realizados nessas áreas são estudados pela historiografia, que analisa o que se tratou nesses campos, daí a configuração como uma metaciência ou metadisciplina. A Figura $3.1^{4}$ dimensiona o trabalho do historiógrafo e seu objeto de estudo, permitindo uma visualização que nos indica a interferência, analítica e interpretativa, em uma realidade de natureza histórica.

4 A Figura 3.1 é reprodução da que MARTINS (2005, p. 137) propõe para suas reflexões acerca da história da ciência e deve ser entendida a partir da seguinte restrição: "O esquema da Figura 1 não deve ser entendido como se a historiografia nascesse de forma indutiva ou automaticamente a partir de documentos e vestígios. Muitos fatores podem influenciar o trabalho do historiador, sua construção de relatos históricos e sua interpretação da história. Esses fatores estão implícitos no contexto histórico em que ele vive e trabalha”. 


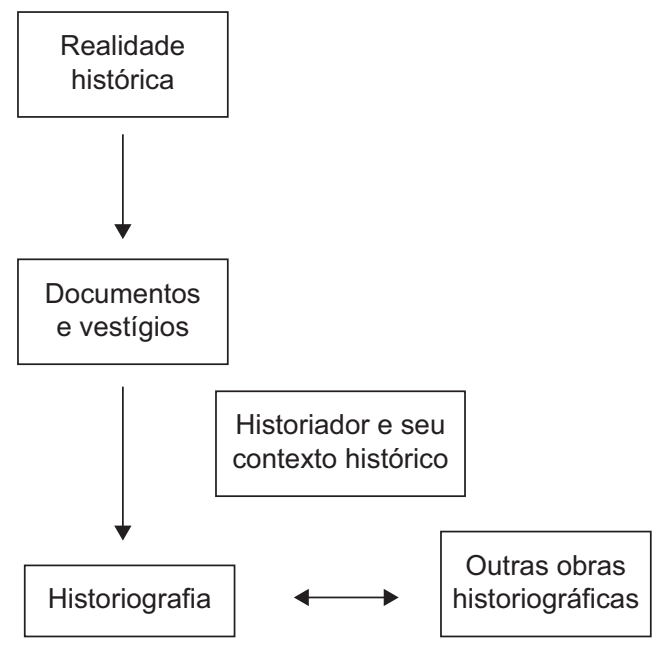

Figura 3.1 0 trabalho do historiógrafo e seu objeto de estudo.

Outro componente da HL é o metodológico (SWIGGERS, 1983), objeto de discussões e debates, pois um campo de estudos relativamente novo encontra no seu caminho diferentes propostas metodológicas para suas práticas. Talvez se deva admitir, como ocorre em diversos campos, a existência de mais de um método apropriado para as abordagens historiográficas sobre a história da linguística.

Considerando a possibilidade da adoção de diferentes direcionamentos metodológicos, deve-se ter em mente que a HL procura, em nome de sua vocação crítica e analítica, razões e causas, observando efeitos do desenrolar do processo histórico. Será em meio a uma apreensão teoricamente orientada de relações causais que possam ser explicativas que se procurará delinear um determinado aspecto da tentativa de observar eventos circunscritos nos diferentes processos constituintes da história dos estudos sobre a linguagem ${ }^{5}$. Encarar a observação historiográfica dessa perspectiva não implica que há ausência de critérios que pautem a análise por elementos científicos; como lembra Le Goff (1984, p. 166): "o historiador não tem o direito de prosseguir uma demonstração, de defender uma causa, seja ela qual for, a despeito dos testemunhos. Deve estabelecer e evidenciar a verdade ou o que julga ser a verdade”.

Diante desse posicionamento, a perspectiva historiográfica que pode dialogar mais satisfatoriamente com a linguística é aquela que se afasta de formas tradicionais da interpretação historiográfica, associadas à linearidade e à noção

5 "O resultado do trabalho do historiador - a narrativa histórica e a interpretação dos fatos históricos - não é algo totalmente objetivo (independente do historiador), nem é algo totalmente arbitrário. Deve ser guiado por princípios éticos, como a imparcialidade [...]"(MARTINS, 2005, p. 138). 
de progresso cumulativo. Além disso, é preciso que se assuma que a historiografia é também uma ciência, capaz, portanto, de dialogar com outra ciência, a linguística. Pensar numa história-ciência é rever a visão tradicional da historiografia e passar a entendê-la como uma história-problema, alicerçada em hipóteses de trabalho e procedimentos metodológicos definidos, na continuidade do pensamento inaugural de Bloch a respeito de uma "história como problema" (BLOCH, 2001).

Manter essa perspectiva problematizadora leva, mais uma vez, a outro diálogo, agora com as ciências sociais e a filosofia, contribuindo, assim, para que fronteiras rígidas sejam substituídas por intermediações, constituindo o espaço de um campo por natureza complexo, formado a partir do deslocamento de limites antecipadamente fixados em direção a diálogos cada vez mais produtivos.

O que se propõe, portanto, é uma configuração complexa da HL, resultante de uma articulação conjunta, interdisciplinar, entre os métodos e as formas de análise da linguística, a história do conhecimento sobre línguas e linguagem, a filosofia e a sociologia da ciência.

Para que esse diálogo se estabeleça, a historiografia pretendida define-se por dois eixos complementares, que delimitam parâmetros internos e externos de pesquisa, ou seja, enfoques internalista e externalista ${ }^{6}$.

Ao enfoque internalista interessa, sobretudo, uma reconstrução dos estudos sobre a linguagem em meio à análise linguística, formulação e reformulação de conceitos teóricos e práticas de tratamento das línguas. Já ao enfoque externalista, o aspecto social como parte do processo histórico de formação e desenvolvimento de uma ciência ou área de saber e de suas práticas discursivas, revelando posicionamentos ideológicos, sociais e históricos, em torno de retóricas (formas e tipos de discurso adotados) de comunidades de pesquisadores e intelectuais. Quando comunidades científicas se organizam em torno de uma retórica de ruptura ou de adesão a um paradigma, a suposta neutralidade do discurso científico ou do conhecimento intelectual coloca-se em meio a um posicionamento que se quer legítimo e ocupa seu lugar social, porque fala de um espaço científico específico e demarcado.

Desse modo, assume-se ser uma das funções da historiografia - numa posição contrária à daqueles que veem a disciplina como mera reconstrução do passado por ele mesmo - a análise, guiada por um ou mais eixos definidos, de afirmações, descrições e interpretações em determinados objetos de análise, com o

6 Levando em consideração externo e interno, diferentes historiógrafos refletiram sobre historiografias content-oriented e context-oriented, no entanto essa dicotomia pode se anular, pois na perspectiva aqui proposta interno e externo estão intimamente relacionados, e, ainda que se possa privilegiar uma visão ou outra em determinado recorte de trabalho, subentende-se que um implica o outro. 
intuito de acompanhar de forma crítica argumentações propostas por autores que as construíram, as quais, de uma maneira ou de outra, acabam por validar (ou não) descrições e análises efetivamente realizadas e suas possíveis conexões com outros trabalhos que chegaram a semelhantes problemas em períodos diversos.

Assim, a delimitação de um conjunto de procedimentos metodológicos da HL reproduz, ela mesma, a interdisciplinaridade presente em sua constituição epistemológica, pois a interpenetração de aspectos externos e internos, em diálogo para que uma interpretação possa ser proveitosamente realizada, espelha a própria constituição do campo que pretende alcançar o conhecimento da história dos estudos sobre a linguagem.

\subsection{A CONTRIBUIC̄ÃO DE MARIA LEONOR CARVALHÃO BUESCU PARA A HL}

Pode-se considerar que muitos estudos em HL produzidos no contexto brasileiro são devedores da contribuição da linguista portuguesa Maria Leonor Carvalhão Buescu, que na década de 1980 iniciou seus trabalhos sobre uma história da gramática em língua portuguesa, voltando-se para as raízes portuguesas, contidas nas obras renascentistas a fim de analisá-las, traçar o seu perfil na época e tentar aplicar o que de melhor oferecem-nos, ainda hoje, esses trabalhos, cujos autores estavam voltados à descrição da língua e ao seu ensino e preocupados com o sentimento de nacionalidade, pois estando abalado o prestígio da língua latina, as línguas vernáculas começavam a atrair o interesse dos estudiosos.

Em Historiografia da Língua Portuguesa, livro escrito por Buescu na década de 1980, aponta-se um traço específico da concepção linguística do Renascimento, que foi, sem dúvida, o interesse pela Retórica e por qualquer prática de linguagem original, elaborada e poderosa, mostrando uma real atração pelas maneiras de se expressar por meio da linguagem nova e exuberante que eles tinham às mãos. Assim, passam a reproduzir textos que fossem acessíveis a um público mais vasto, uma vez que falavam uma linguagem mais próxima a eles. As questões que se impõem nesse momento são concernentes à dialética entre a língua usada pela elite privilegiada da cultura - a língua latina - e a língua utilizada pela não elite - a língua vernacular. Tal situação leva os mestres a uma atitude paradoxal, pois, segundo Buescu (1975), ao lado da tendência da volta aos modelos clássicos na época do classicismo renascentista, havia a atitude presencialista de valorização da língua vulgar que já era utilizada pelos autores de prestígio em suas obras.

O trabalho de historiografia realizado se espraia pelos renascentistas que são levados a rever o conceito e o esquema gramatical latinos, para que estes correspondessem às línguas modernas; sendo assim, o seu contexto cultural leva-os a obedecer a dita atitude presencialista, buscando normas para a língua que, efetiva- 
mente, usam, levando em conta o uso da linguagem da época, procurando esquecer o passado, ignorando o latim e observando a realidade atual e visível, que os leva a considerar as línguas vernáculas como "línguas sem passado" (BUESCU, 1978, p. 54). Paradoxalmente ao incremento do uso do latim pelos eruditos do Renascimento, com a volta aos clássicos: Cícero, Tito Lívio, Virgílio, Horácio e Plínio, há a criação da Gramática das línguas novilatinas, pois a maturidade de tais línguas modernas é evidente. Isso explica terem, a maior parte dos gramáticos do renascimento, subordinado o esquema de suas obras aos esquemas da Gramática Latina.

Buescu, com esses posicionamentos, centrada em autores clássicos e historiadores, tem uma atitude semelhante à de um historiógrafo da linguística, pois escreve a história do saber linguístico com o objetivo de descrever e explicar como se adquiriu, produziu e desenvolveu o conhecimento linguístico no momento quinhentista. E está nesses posicionamentos assumidos pela autora alguns dos primeiros direcionamentos de pesquisa que conduziriam à moderna HL tal como a entendemos hoje, influenciando sobremaneira grupos de pesquisadores que no Brasil, na década de 1980, já começavam a se interessar pelo olhar histórico a respeito do desenvolvimento dos estudos da linguagem. Em muitos dos trabalhos feitos hoje por pesquisadores interessados em uma história da gramática, há a permanência dos traços e das perspectivas de Buescu, sendo que é difícil pensar em uma atividade historiográfica sobre o pensamento gramatical em língua portuguesa sem considerá-la uma líder intelectual e influência perene em trabalhos que hoje são desenvolvidos, por exemplo, pelos pesquisadores que se filiam ao Grupo de Historiografia da Língua Portuguesa, na PUC-SP.

\subsection{A HL NO BRASIL E OS GRUPOS DE PESQUISA: A INSTITUCIONALIZAC̣ÃO DA ÁREA}

No Brasil, uma abordagem de natureza histórica sobre os estudos da linguagem teve seu desenvolvimento já a partir da década de 1970, quando alguns trabalhos ensaiaram tentativas de reflexões sobre desenvolvimentos da linguística brasileira (cf. BATISTA, 2013), mas foi de fato na década de 1990 que os trabalhos desenvolvidos no âmbito das propostas de uma Historiografia da Linguística ou de uma História das Ideias Linguísticas, articuladas, entre outros, por Konrad Koerner, Pierre Swiggers e Sylvain Auroux, alcançaram maior divulgação e reconhecimento acadêmico, principalmente por conta da criação dos primeiros grupos de pesquisa que se organizaram prioritariamente em torno de propostas de reconstrução historiográfica de aspectos da pesquisa linguística brasileira.

Podem-se apontar grupos de destaque em âmbito nacional, ainda que não compartilhem, muitas vezes, métodos e objetivos:

a) na Universidade de São Paulo, há o pioneiro Grupo de Estudos em Historiografia da Linguística, do Centro de Documentação em Historiografia 
da Linguística (CEDOCH, Departamento de Linguística da USP). Os estudos do grupo alcançam diferentes objetos de pesquisa, mas há de fato nos últimos anos um direcionamento para trabalhos sobre a linguística missionária e a constituição de acervos documentais;

b) congregando pesquisadores de diferentes estados e universidades, há o Grupo de Pesquisa em Historiografia da Língua Portuguesa do IP-PUC/SP (GPeHLP), constituído com o objetivo de elaborar projetos voltados para a reflexão sobre textos linguístico-gramaticais lusófonos que dialoguem entre si no que concerne às questões formadoras dos sujeitos escolarizados em língua portuguesa, unindo não só a produção gramatical de autores de prestígio e dos produtores de material didático, bem como a dos legisladores que, de uma forma ou de outra, impuseram um determinado caminho a ser seguido por professores-educadores no decorrer dos séculos XVI ao $\mathrm{XX}$. As pesquisas selecionam, ordenam e reconstroem o conhecimento linguístico, com base na interpretação crítica do processo discursivo dessa produção contextualizada do ponto de vista histórico, social e cultural. O objeto de pesquisa com foco nos séculos XVI, XVII, XVIII e XIX foram gramáticas portuguesas e brasileiras. No século XX, o objeto de pesquisa foram os materiais didáticos e a legislação que rege sua elaboração. $O$ foco, neste momento, está nas mesmas produções brasileiras das décadas de 1960 a 1990, tendo como objetivos específicos: - verificar como o ensino de língua materna se processa a partir das políticas linguísticas efetivamente implementadas na segunda metade do século XX; - compreender as políticas linguísticas estabelecidas no Brasil por meio da análise de documentos; - identificar aspectos da normatização do português no período selecionado e sua implicação no ensino de língua portuguesa. Os resultados de pesquisa desse Grupo têm sido compilados numa coleção intitulada História Entrelaçada, que está hoje no quinto volume, estando prevista para 2014 a publicação dos capítulos que compõem o livro História Entrelaçada 6, todos elaborados por membros do GPeHLP.

Os projetos do GPeHLP se organizam em três eixos: Gramaticografia, Fontes Historiográficas e Interculturalismo. O primeiro item divide-se em Prática Teórica composta pelos projetos Gramáticas do Português século XXI, Língua Portuguesa Novecentista e Teoria Construturalista; e Prática Pedagógica composta pelos projetos Interface entre linguística e ensino do Português, Obras Pedagógicas de Mattoso Câmara e Manuais do Professor. O segundo item compõe-se do Projeto $1^{a}$ Pessoa, com previsão de se entrevistarem mulheres linguistas do século XX: Ingedore Koch, Mary Kato, Maria Helena de Moura Neves e Elisa Guimarães. Por fim, o terceiro item Interculturalismo aborda a Lusofonia no projeto Relações culturais, linguísticas e identitárias. 
Esse grupo, a partir de seus eixos nucleares de pesquisa, no desenvolvimento de seus projetos, articulou-se a Instituições de Ensino Superior (IES) representativas no cenário da Pós-Graduação no Brasil, especificamente em São Paulo, de onde surgiram os primeiros parceiros, linguistas brasileiros, interessados em pesquisas sobre HL, quais sejam: Universidade de São Paulo (USP), Pontifícia Universidade Católica de São Paulo (PUC/SP) e Universidade Presbiteriana Macknzie (UPM). Com a ampliação do escopo dos projetos, ampliou-se também, e na mesma medida, a rede de contatos com outras universidades do Brasil e de São Paulo, como por exemplo: Universidade Estadual do Maranhão (UEMA), Universidade Estadual do Mato Grosso do Sul (UEMS), Universidade Cruzeiro do Sul (UNICSUL/São Paulo);

c) além desses grupos com coordenação concentrada no estado de São Pau$1 \mathrm{l}^{7}$, há, como mencionado, na ANPOLL o Grupo de Trabalho em Historiografia da Linguística Brasileira (GTHLB), com pesquisadores de todo o Brasil, além de estudantes de pós-graduação. Também podem ser apontadas organizações mais recentes, como o projeto de trabalho internacional na Asociación de Linguística y Filología de América Latina (Alfal) e o grupo da Associação Brasileira de Linguística (Abralin). Esses grupos oficializaram, por assim dizer, as linhas de pesquisa historiográfica no contexto brasileiro.

O Grupo GTHLB, como dissemos na introdução, se constituiu em 1996, reunindo pesquisadores de várias partes do país, vinculados a Programas de Pós-Graduação de diferentes Universidades. O interesse pela preservação da memória dos estudos linguísticos no Brasil uniu e une esse Grupo, que mantém cinco grandes linhas de pesquisa que fazem parte das atividades do GT: a) organização de acervos e criação de bancos de memória sobre produção linguística brasileira; b) Linguística Missionária: para uma história das práticas linguísticas, tendo como objeto de pesquisa as gramáticas, catecismos e vocabulários produzidos pelos missionários que atuaram no Brasil nos tempos coloniais; c) Gramaticologia e Gramaticografia da Língua Portuguesa, abordando a evolução do pensamento gramatical no ensino de Português, do século XVI ao XX; d) Políticas Linguísticas Lusófonas e ensino de línguas sob uma perspectiva historiográfica; (e) o tratamento da diversidade linguística $^{8}$. A Figura 3.2 possibilita uma visualização dessas linhas de trabalho.

7 Naturalmente que o recorte que aqui realizamos não implica desconsiderar a presença de outros grupos com pesquisa atuante no cenário brasileiro. A delimitação ocorreu para que se pudesse oferecer de modo detalhado pelo menos algumas das perspectivas de análise em HL empreendida no Brasil.

8 As linhas apontadas representam possibilidades de direcionamento das pesquisas em HL, principalmente aquelas definidas pelo plano de trabalho do grupo para o biênio 2012-2014. Para maiores informações, pode ser consultada a página do grupo em <http://anpoll.org.br/gt/historiografia-da-linguistica-brasileira/wp content/uploads/sites/17/2013/03/Plano-de-Trabalho-2012-2014.pdf>. 


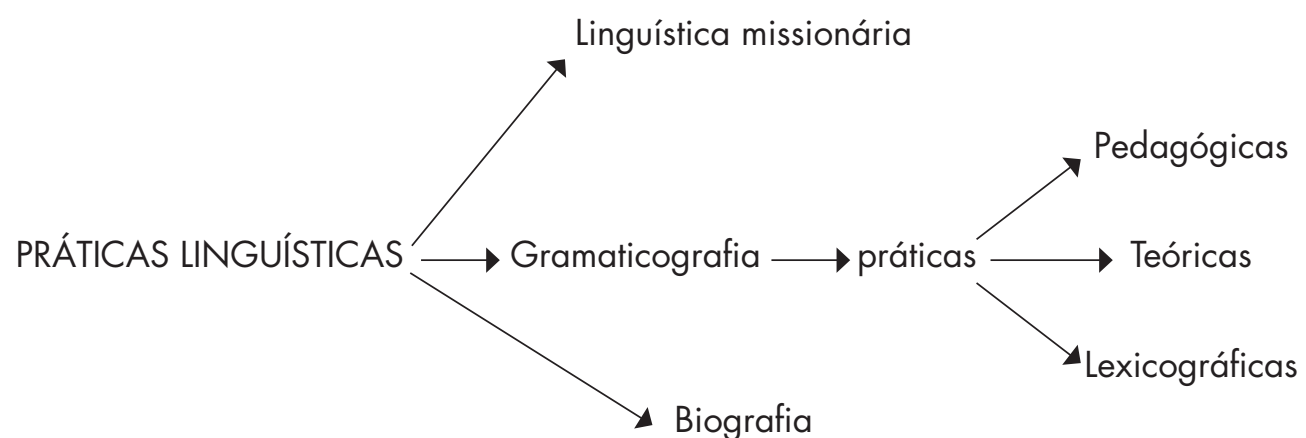

Figura 3.2 Linha de pesquisa historiográfica no contexto brasileiro.

Os pesquisadores reunidos no GT estão envolvidos com o estudo de obras de acervos brasileiros importantes, como o da Biblioteca Nacional, e de acervos estrangeiros com obras de interesse para o Brasil, como a Biblioteca Nacional de Portugal, a Biblioteca da Universidade do Porto, a Biblioteca Nacional de Paris, a biblioteca da Brown University. É inegável a importância desse trabalho para o conhecimento de nossa própria identidade nacional e de nossa História. Dessa forma, preocupam-se com a continuidade da preservação da memória dos estudos linguísticos no Brasil, atuando na formação de novos pesquisadores, ao se responsabilizarem por orientação de alunos de graduação e de pós-graduação nessa área de estudos. Como mencionado, foi feita a escolha teórica pelos enunciadores do modelo a ser divulgado e tem-se hoje, persuadidos os enunciatários aderentes ao grupo nova constituição temática, adaptada aos novos interesses investigativos do Grupo.

Cabe mencionar, também, que, na década de 2000, começaram a dar resultado as tentativas de colocar a reflexão historiográfica no panorama de formação em Letras. Centros de ensino e pesquisa como a Universidade de São Paulo (USP), a Universidade de Campinas (Unicamp), a Universidade Estadual de São Paulo (Unesp) e a Universidade Presbiteriana Mackenzie (UPM), para ficar apenas em alguns exemplos restritos ao estado de São Paulo, oferecem como parte do elenco de disciplinas dos cursos de bacharelado, licenciatura, especialização, mestrado e/ou doutorado cursos que colocam em pauta a história dos estudos sobre línguas e linguagem.

Entre os trabalhos que, especificamente no Brasil, contribuíram para que o campo alcançasse legitimidade e reconhecimento na área dos estudos linguísticos (e consequentemente a compreensão de sua importância para a reflexão a respeito do que entendemos como pesquisa em ciência da linguagem) pode-se apontar uma tendência de avaliar áreas específicas, procurando dar conta do estado da arte, alcances e perspectivas, assim como uma tendência em destaque para ampliar a análise de uma história da gramática brasileira, em relação com as tradições ibéricas, e de uma linguística missionária, além de pesquisas sobre formas e modos do ensino de língua. 


\subsection{DOS PROPÓSITOS DE ESTUDAR A HISTÓRIA DOS ESTUDOS DA LINGUAGEM}

Koerner (1999) procura apontar funções da HL, tendo em vista, em última instância, legitimar a própria área de pesquisa. Em primeiro lugar, é preciso estabelecer que o conhecimento histórico de uma ciência e de uma área de saber pode tornar o pesquisador e o estudioso de um campo um verdadeiro cientista ou intelectual. Será, nessa perspectiva, a partir do conhecimento do desenrolar histórico das ideias linguísticas que uma formação completa do linguista se estabelecerá. Em segundo lugar, pode-se apontar que a HL tem como uma de suas funções oferecer uma introdução à linguística para um pesquisador que, enfrentando a pluralidade das ciências da linguagem, queira compreender avanços e recuos em propostas de análise linguística, continuidades e descontinuidades em modos de tratamento dos fenômenos das línguas; enfim, queira alcançar uma visão panorâmica do que se produziu e se produz em termos de estudos sobre a linguagem. $\mathrm{E}$ ainda há a possibilidade de que, na construção analítica de um conhecimento sobre a circunscrição histórica dos estudos linguísticos, podemos chegar próximos ao estágio de reflexão apontado por Swiggers (2010): “A historiografia linguistica faz perguntas linguisticamente relevantes sobre as 'práticas historicamente relacionadas à linguagem: assim, historiógrafos da linguística podem, ou devem, oferecer insights aos linguistas interessados 'no que estão fazendo"'.

\subsection{CONCLUSÃO}

A HL, tal como a expusemos em linhas introdutórias neste texto, configura-se como uma narrativa que procura recuperar de modo crítico e interpretativo uma série de atitudes cognitivas, sociais e institucionalmente contextualizadas, que instauram produções de conhecimento em diferentes recortes temporais, caracterizando, assim, a construção dos saberes inseridos em uma inevitável temporalidade. Cabe, portanto, ao historiógrafo analisar os modos de historicização desses conhecimentos situados em espaços discursivos e ideológicos que promovem não só a produção de teorias e métodos, mas também sua legitimação e divulgação em grupos.

Esses atos de saber sobre a linguagem, uma vez que elaborados e difundidos por pesquisadores envoltos em complexas redes sociais e discursivas de circulação de ideias, requerem uma análise teórica e metodologicamente orientada, que possa reconstruir o pensamento sobre a linguagem em dois eixos de reflexão intrinsecamente relacionados na tentativa de elaborar uma história das comunidades científicas e também uma história dos textos científicos. E a tarefa desse historiógrafo se construirá e reconstruirá em permanente perspectiva de reflexão a respeito do método utilizado e das questões propostas, pois serão as interroga- 
ções feitas pelo pesquisador o elemento articulador de uma história que busca sua fundação e estrutura na problematização.

O poeta Carlos Drummond de Andrade faz uma bela reflexão sobre o tempo e a história no poema "História, coração, linguagem" (1980), e está no verso Tu és a história que narraste o eixo para concluir nossas reflexões, pois a arte do ofício do historiógrafo encontra-se, ela mesma, na seleção das ferramentas e dos procedimentos de análise, permitindo que a História seja reconstruída e compreendida a partir do momento em que começa o discurso do sujeito que interpreta os vestígios que encontra na busca por uma memória não contemplativa, mas interpeladora de sentidos que se relacionam com o que foi, o que é e o que ainda será. Nesse sentido, na compreensão de que o questionamento histórico é derivado das práticas analíticas adotadas pelo historiógrafo, é que uma área como a HL encerra sua contribuição no amplo e diversificado espaço de reflexões das ciências da linguagem. E na mesma linha do poeta: será o modo de olhar e interpretar os eventos históricos que na mesma direção os reinaugurarão a cada perspectiva analítica que se construa.

\section{REFERÊNCIAS}

BATISTA, R.O. Introdução à Historiografia da Linguística. São Paulo: Cortez, 2013. BLOCH, M. Apologia da história ou o ofício do historiador. Tradução de André Telles. Rio de Janeiro: Jorge Zahar, 2001.

BUESCU, M.L.C. Gramáticos portugueses do século XVI. Lisboa: Breve, 1978.

BUESCU, M. L. C. Historiografia da Lingua Portuguesa - século XVI. Lisboa: Livraria Sá da Costa Editora, 1984.

DRUMMOND DE ANDRADE, C. A paixão medida (1980). In: Carlos Drummond de Andrade. Poesia e Prosa. Rio de Janeiro: Nova Aguilar, 1992.

KOERNER, E.F.K. What is the History of Linguistics Good for? Beiträge zur Geschichte der Sprachwissenschaft, n. 9, p. 209-230, 1999.

KOERNER, E.F.K. La Historiografía de La Lingüística. Pasado, Presente, Futuro. In: DORTA, Josefa; CORRALES, Cristóbal y CORBELLA, Dolores (Eds.). Historiografía de La lingüistica en el âmbito hispânico: fundamentos epistemológicos y metodológicos. Madrid: Arco Libros, S.L., 2007.LE GOFF, J. (Org.). Memória - História. Lisboa: Imprensa Nacional: Casa da Moeda, 1984.

MAINGUENEAU, D. Doze conceitos em análise do discurso. In: POSSENTI, S; SOUZA E SILVA, M. C. P. de (Org.). São Paulo: Parábola, 2010.

MARTINS, R.A. Ciência versus historiografia: os diferentes níveis discursivos nas obras sobre história da ciência. In: ALFONSO-GOLDFARB, A.M.; BELTRAN, M.H.R. (Ed.) Escrevendo a História da Ciência: tendências, propostas e discussões historiográficas. São Paulo: EDUC/Livraria de Física/Fapesp, 2005, p. 115-145. Disponível em: <http:// ghtc.ifi.unicamp.br/pdf/ram-111.pdf>. Acesso em: 
MURRAY, S. O. Theory groups and the study of language in North America: A social history. Amsterdam, Philadelphia: John Benjamins, 1994.

OLIVEIRA, F. de. Grammatica da Lingoagem Portuguesa. Introdução, leitura actualizada e notas: BUESCU, M. L. C. Lisboa: Imprensa Nacional: Casa da Moeda, 1975.

SWIGGERS, P. La méthodologie de l'historiographie de la Linguistique. FLH 4, p. 5579, 1983.

SWIGGERS, P. Creuser dans l'histoire des sciences du langage: vers une archéologie du savoir linguistique. La Licorne, n. 19, p. 115-134, 1991.

SWIGGERS, P. História, Historiografia da Linguística: status, modelos e classificações. Eutomia (revista online), 2010. Disponível em: <http://www.revistaeutomia.com.br/>. Acesso em: 
